\title{
Pathology of apprenticeships for masters of nursing critical care
}

\author{
Fatemeh Ghaffari ${ }^{1}$, Nahid Dehghan Nayeri ${ }^{2}$, Faezeh Norouzinezhad ${ }^{3}$, Zahra Tayebi $^{4}$
}

${ }^{1}$ Ph.D. of Nursing, Assistant Professor, School of Nursing and Midwifery, Ramsar Nursing Care Research Center, Babol University of Medical Sciences, Babol, Mazandaran, Iran

${ }^{2}$ Ph.D. of Nursing, Professor, School of Nursing and Midwifery, Nursing and Midwifery Care Research Center, Tehran University of Medical Sciences, Tehran, Iran

${ }^{3}$ M.Sc. of Nursing, School of Nursing and Midwifery, Ramsar Nursing Care Research Center, Babol University of Medical Sciences, Babol, Mazandaran, Iran

${ }^{4} \mathrm{Ph} . \mathrm{D}$. of Nursing, Assistant Professor, Faculty of Nursing and Midwifery, Alborz University of Medical Sciences, Karaj, Alborz, Iran

\section{Type of article: Original}

\begin{abstract}
Introduction: The increasing complexity of patient care conditions in intensive care units, along with the development of these units, has increased the need for qualified nurses and health professionals. Therefore, due to recent changes and in response to the shortage of capable nurses, a master's major in intensive care nursing has been created. One of the main challenges of this curriculum is to ensure that graduates have the required competencies. The current study aimed to explain the pathology of apprenticeships for a masters in nursing critical care.

Methods: This qualitative study was conducted for masters in nursing critical care students of Tehran University of Medical Sciences in 2014-2015. The sampling was purposeful. Data were collected through face-to-face interviews with 15 students. Conventional content analysis was used to analyze the data.

Results: Three categories "ineffective management, unfavorable context for achieving skills, and lack of clinical instructors and sufficient competence" were extracted.

Conclusion: Preparing settings for entering students such as having an adequate training field and expert educators, providing conditions for orientation of educators and participation in the related workshops, and recruitment of experienced instructors in the apprenticeships field can increase the quality of MS levels.

Keywords: Intensive care nursing, Student, Content analysis, Apprenticeship
\end{abstract}

\section{Introduction}

Increasing complexity of patient care conditions in intensive care units and expansion of these units over the past 30 years has increased the need for competent nurses with a unique body of knowledge (1). The main philosophy of preparing nurses to work in intensive care units is to ensure the safety and quality of patient care; hence the curriculums should be more clinical and competency-based and adapted based on practice-based approaches (2). Nurses of different units need to have intensive care experiences because caring for critically ill patients is not limited to ICUs, and patients' situations are typically complex in most wards. Nurses who work in different units are expected to manage the challenges of patients with complex disorders under monitors and multiple supportive technologies (3-5). However, shortage of expert nurses is a global reality and will be more severe with the population increasingly getting older (6). Intensive care units are often known to have inadequate staff, nurses' willingness to change their ward, illness, and absence of shifts. Hence, employment of new graduates in these units is created despite the lack of preparation or lack of sufficient expertise (1). However, the need for qualified nurses for patients' care is examined more than ever with increasing awareness of patients. Therefore, attracting and

\section{Corresponding author:}

Professor Dr. Nahid Dehghan-Nayeri, Tehran University of Medical Sciences, Tehran, Iran.

Tel: +982166937120, Fax: +982166904252, E-mail: nahid.nayeri@gmail.com

Received: May 10, 2016, Accepted: August 20, 2016, Published: January 2017

iThenticate screening: August 30, 2016, English editing: October 19, 2016, Quality control: December 02, 2016

(C) 2017 The Authors. This is an open access article under the terms of the Creative Commons Attribution-NonCommercialNoDerivs License, which permits use and distribution in any medium, provided the original work is properly cited, the use is non-commercial and no modifications or adaptations are made. 
retaining the best expert staff is an impressive and vivid challenge. Therefore, intensive care nursing graduates can be valuable sources of acute and intensive care (6). Because major intensive nursing care has been established in response to the shortage of proficient nurses and recent changes in the units, the importance of students' experience for caring in intensive units remains clear. An intensive and specialized environment should be an ideal environment for generating and enhancing knowledge and skills in various areas $(4,7)$. The unpredictable nature of intensive care units creates the possibility that students cannot gain different and necessary learning experiences for increasing their skills. In addition, some curriculum factors may facilitate or impede the acquisition of knowledge and skills (1). Apprenticeship is an integral, inseparable, and most important part of nursing education. It is known as the heart of nursing curriculum. Clinical education is essential in forming basic skills and professional competencies of nursing students. Improving the quality of clinical education requires continuous assessment of the current situation and identifying its strengths and weaknesses. In this regard, opinions and experiences of students can help to develop future curriculums. Some factors such as undervalued clinical education, insufficient clinical instructors, lack of a permanent coach to address the education needs, and the lack of incentives for students have been proposed as problems from the students' viewpoints (8). Apprenticeship in intensive units is much more important than in the general units. However, despite having a strong theoretical basis, nursing graduates typically do not have the skill and expertise in clinical settings, and they are weak in the process of problem solving. Lack of planning for clinical education is the cause of some problems (9). In regard to specialization of intensive units and the need for qualified nurses, a post-graduate-level curriculum of intensive care was held in Iran in 2008 for the first time. Students have been entered to the MS level immediately after graduation of BS, or they have a lot of nursing experience. However, it is expected that the curriculum will be a fit for both groups with different needs. Therefore, this curriculum requires evaluation due to its long run and various challenges. One of the main challenges of any educational curriculum is to ensure graduates have the necessary competencies; hence it is necessary to pay particular attention to the effects of the curriculum (10). One of the most essential parts of the curriculum evaluation is to assess the experiences of students of their apprenticeships. This can contribute to quality improvement of the programs in later stages. Researchers also believe that student feedback on modules and programs can affect a program's development (5). Because profound understanding of the challenges of apprenticeships of the curriculum is not achievable with quantitative approaches, the researchers decided to achieve this aim by qualitative study. The current study aimed to explain the pathology of apprenticeships for obtaining a masters in nursing critical care.

\section{Material and Methods}

\subsection{Setting}

This is a qualitative content analysis study that students of Tehran University of Medical Sciences were invited for which to contribute in 2015. Purposive sampling was used to collect data. We conducted 15 face-to-face semistructured interviews.

\subsection{Data collection}

First, students were asked to explain their experiences in apprenticeships. Then, they were asked to explain the barriers and facilitators that have an effect on the apprenticeships. We asked what students experienced in this program. Their experience in clinical education. The factors and obstacles in achieving the goals of clinical education. In regard to the answers of participants, further clearing questions were asked. The interviews lasted from 35 to 45 minutes based on participants' willingness to respond and their tolerance. All interviews were recorded by digital devices. Interviews were done in the researcher room in the school of nursing or everywhere the participants were comfortable. Data collection began in 2014 and continued until 2015.

\subsection{Data analysis}

The interviews were analyzed by Lundman and Graneheim approach (11). The interviews were typed immediately after recording. The interviews were read several times in order to achieve the overall understanding of the participants' statements about the study objectives. Data were coded in three levels: The meaning units or initial codes were extracted; then codes were merged and classified according to similarities and differences; finally, themes were extracted as the third level of data.

\subsection{Trustworthiness}

We used Guba and Lincoln criteria for rigor (12). A researcher was present in the field for a long time. Results were confirmed by participants, and members of research team checked the process of coding. The maximum variant sampling technique (different age, gender, job experience, and distance between graduations of BS to entering in the 
MS) was used. Researchers recorded and reported the study process in detail to provide the possibility of transferability for other researchers.

\subsection{Ethical consideration}

The research study was approved by the research committee of Tehran University of Medical Sciences, international campus (TUMS-IC) with ref. number 13009. Subjects were informed about the study aim; if they would like to participate in the study, they signed a written consent. Time and place of the interview were determined with the agreement of participants. Participants permitted voice recording. They were assured about confidentiality of their personal information and maintaining anonymity in their documents related to research. The participants were allowed to withdraw from the study at any time.

\section{Results}

Three categories were extracted from analysis of data: ineffective management, unfavorable context for achieving skills, and lack of clinical instructors and lack sufficient competence (Table 1).

Table 1. Categories and Subcategories

\begin{tabular}{|l|l|}
\hline \multirow{5}{*}{ Ineffective management } & Educational contract \\
\cline { 2 - 2 } & Escape responsibility \\
\cline { 2 - 2 } & Ineffective planning \\
\cline { 2 - 2 } & Abandonment of nursing care \\
\cline { 2 - 2 } & lack of clinical group manager \\
\hline Unfavorable context for achieving skills & System resistance \\
\cline { 2 - 2 } & Specialization as an unreachable goal \\
\cline { 2 - 2 } & Non-cooperative observation \\
\cline { 2 - 2 } & Abuse of students as auxiliary troops \\
\hline Lack of clinical instructors and lack sufficient competence & Lack of experienced mentors \\
\cline { 2 - 2 } & Lack of specific educational process \\
\cline { 2 - 2 } & Irresponsibility under in the form of mentoring \\
\hline
\end{tabular}

\subsection{Ineffective management}

This category consists of five subcategories: educational contract, escape responsibility, ineffective planning, abandonment of nursing care, and lack of clinical group manager.

\subsubsection{Educational contraction}

Lack of a clinical education field is one of the main reasons for condensing and cancelling many important parts of the education process. Most students do not have the opportunity to gain experience in curriculum apprenticeship outlines. Educational contraction caused MS critical care nursing students to not experience the differences between undergraduate apprenticeships and MS level. Students expressed their reluctance, and frustration is an outcome of repetitive clinical education and removed particular topics. "Apprenticeships were short and did not have a specific and clear process. It takes a week to get familiar with personnel, begin to communicate with them. It will be too late to teach us. It is too short; one day we say hello, another day we say good bye (p4)." "In a reasonable time frame it is good; but not only for 3-4 hours. I didn't learn anything. This kind of apprenticeships is not a good time to learn; I think critical care should be consistent based on my experience. For example, if I injected a medication, I should wait to see if the changes create in the patient. If I don't have any changes for what I must do, this may require critical thinking. But we were at the wards only 3-4 hours. We just talked together, and we didn't learn anything when we were at critical units (p10)." Lack of educational experience in some units, missing some important parts, and little time for apprenticeship were other symptom of educational contraction. "CCU period was very short, while CCU is a world. And I haven't experienced Open Hart ICU until now (p1)".

\subsubsection{Escaping of responsibility}

According to most participants' point of view, learning does not happen; the educational effectiveness is trivial and a kind of abandonment. The outcome of such apprenticeships is incompetent graduates for critical care units. Clinical training period in conditions such as lack of holistic view to patient needs, lack of learning due to interrupted apprenticeships and non-continuous caring, technical instead patient-center education, having to do routines, and poor patient advocacy roles are some of escape responsibilities of the educational manager. "We should consider patients to be comprehensive; the medication and treatment should not be the only things we consider. We shouldn't look at patient as an object. We don't achieve this aim in the apprenticeships. But if patients 
assign to me, I'll decide for her/him. For example, I say we should choose this regimen for this diabetic patient. Then, we can consider the results. We check and follow-up the patient as a whole, and I'll see the result. But we didn't have such a clinical education (p15)." "We weren't actually assigned the responsible. It was to the extent of gavage. They permanently told us to gavage. We are exhausted (p5)."

\subsubsection{Ineffective planning}

Setting goals of apprenticeship is a problem, in addition to planning them by clinical managers is among the problems that students facing in clinical education. The short duration of the internship, unfit planning, and interrupted apprenticeships has led students to remain busy all week. Long day clinical education creates interference between classes and internships. This leads to problems such as absenteeism and interruption in the apprenticeships. Poor planning leads to some apprenticeships to be contracted. The lack of clarity in the clinical education program leads to a waste of time of students. "We were there two long days, and we didn't have any energy and can't tolerate the afternoons. We really do not understand how that day is going. And this planning has reduced our efficiency (p8)." "One of the worst planning for our apprenticeship was when we were in the Open Hart ICU. When patients went for surgery, they were brought to the ward at 2 o'clock in the afternoon; and we were not able to care of them because we were there only to 12 in the midday (p11)." "Theory and clinical education held at the same time, and this does not work for us. It was good, if there was a distance between them (p6)."

3.1.4. Abandonment of nursing care

According to participants, education in the use of equipment and explaining many of the procedures in more detail were beneficial for education given by specialists in clinical education. However, irregularities in the presence at wards of instructors, inattention to teaching, and lack of their nursing views were frequently seen in participants' statements. Lack of nursing view leads to the elimination of nursing theories in clinical education. From the students' perspective, recruitment of physicians as clinical instructors causes clinical education to be theoretical. "The instructors are recruited to engage students at the clinical caring and convey to them what they know (p2)." "Now we need to recruit physicians because this field is new and specialized. But we don't use them a lot and should balance. We shouldn't deny the need for a physician for education. But we shouldn't have an overdependence on them (p13)." "Sometimes we, as critical care nursing students, have gone to the wards and waited about an hour for a medical doctor. And when they came, they paid attention to their interns, and we had to stand and only observe. Not only our character isn't preserved, but also we didn't have any useful education (p3)."

\subsubsection{Lack of clinical manager}

According to participants' views, the lack of a clinical manager who can play the role of the clinical fund manager and have the necessary power in the clinical setting is one of important factors that can lead to be ineffectiveness of apprenticeships. Clinical managers can play an important role in learning in order to bridge the gap between hospitals and faculty. They have an influential role on cooperation nurses, educators, and students, changing hospital administrator's attitudes in relation to clinical education and its importance, providing opportunities for using specific equipment in the wards and recruitment of skillful educators as a mentor. "They do not allow us to do specialized work because clinical staff doesn't have a good relationship with faculty. This means the school of nursing doesn't dominate clinical settings for training their critical care students and tell them they should do these works. The nurse does not allow us to achieve what we want. Finally, they say to inject a serum-or melt the medications (p14).

\subsection{Unfavorable context for obtaining skills}

This category consists of four subcategories including system resistance, specialization as an unreachable goal, noncooperative observation, and abuse of students as auxiliary troops.

\subsubsection{System resistance}

Most participants believe that most head nurses are not certified for this kind of apprenticeship and the major and its level is typically not clear to them. As a result, the clinical environment is unfavorable for obtaining skills. "When we go to the ward, the head nurse frowns on us and say again they come! When we want to try something, she says no, you don't allow doing this or that. We really were carefree ( $p 7)$." Introduction to equipment and procedures creates an important part in clinical education courses. However, clinical education fields are not eligible for students, and this may cause lack of being familiar with the equipment and practicing procedures. Prohibition by head nurses and other managers are the most important system barriers. "That time we should have spent on a procedure, there wasn't time, even if a person taught us about intubation difficulties (p15)." “There wasn't a medical equipment engineer to explain the general structure of ventilator. We do not know where the alarm is and what the alarm is for. What are its routes? If we had learned them, we could have learned other things. The problem is that a doctor tells us only its function (p2)." "If CPR happened in our ward, we could handle it. The instructors should guide us, and we do it, so we learn its theory and practical aspects. But we couldn't get these things. Or we 
could set ventilator in accordance to $A B G$ and know what changes can be made when the $A B G$ is like this. None of this was said to us (p13).

3.2.2. Specialization: inaccessible goal

Although one of the main motivators of students in a critical care nursing major is specialization, most participants found that the quality and quantity of apprenticeships are not suitable for achieving this goal. Changing some of clinical education from critical units such as ICU, CCU, and dialysis to general wards causes students to be dissatisfied of results of clinical training periods. The students often do not find these units as an appropriate clinical environment for specialized care. Lack of distinction between undergraduate and postgraduate clinical education keeps them far from achieving the purpose of critical care nursing. Therefore, they tend to gain experience and skills in medical procedures. "I often went to the general wards. What could we learn in these wards? We only write nursing report and patients' history. The ICU didn't have capacity, and they didn't bring us there. That wasn't a good apprenticeship. The only idea was they want us to spend that clinical period without any clear goal (p4)."

"The wards we have been to for apprenticeship have a big difference with the ICUs where we could place the tube for patients, or there are a lot of patients with complex situations. We are not encountered with any of these situations. I just saw them in the book and films that I have already searched (p10)."

3.2.3. Only non-participatory observation

Participants believed that the policies of clinical centers have caused a lot of nursing care to be taken by medical students, including interns, due to shortages of nurses and overcrowding. Nursing students typically do not find opportunities for acquisition of skills due to the limited field of education and experience requirements. "It was just observation. They did not allow us to do anything. For example, you want to put an NG tube, but the interns allow doing it. Or the patients are intubated by anesthesiologist. We weren't allowed to do specialized work (p1)." "Patients were not enough for our instruction. We were about six students, and the ward has only two patients. The instructors were not able to do anything, and they waited to finish our apprenticeship. We were only observer (p8)." 3.2.4. Abuse of students as auxiliary troops

Recruiting students as auxiliary troops and delegating routine and non-nursing care to them have caused them to get frustrated and abused physically and emotionally. Students believe that they should spend time on routines and nonspecific care instead of learning and obtaining skill because of lack of staff and irresponsibility of nurses and instructors. Sometimes they are forced to do non-professional activities to help head nurses. They simply play an auxiliary role. "Our internship program is really a problem. One problem was the long days. It was really hard to work from 7 am to $7 \mathrm{pm}$. We did not have a coach. They assigned us to the wards and said we should work a lot (p10)."

\subsection{Lack of adequate clinical instructors and their competency}

This category consisted of three subcategories: lack of experienced mentors, lack of specific educational process, and irresponsibility under in the form of mentoring.

\subsubsection{Lack of experienced mentors}

Recruitment of less experienced and fresh graduates as clinical instructors is one of the factors leading to lack of skills and decreasing the incentive for students in clinical situations. This can reduce student confidence and lead to frustration and lack of trust in other instructors. On the other hand, the quality of care provided is not satisfactory. The instructors can be a negative model due to inducing fear and uncertainty among students. According to most students, recruitment of nursing staff and $\mathrm{PhD}$ students as an instructor is a main challenge in clinical education due to lack of experience, competency, and skills. "Why they should have recruited such an instructor for critical care student, when they do not even dare to come near the patient. He even feared when he wanted to put off the patient's chest tube. It was clear he wanted experts. When we were in the Open Hart ICU for 6 to 7 days, we only looked at each other. They should choose an instructor who is a master, and we can learn of that person. That is, they must know more than us (p12)." "Our critical care professors didn't take our clinical education. If they covered our apprenticeships, it was more useful. But they engage with researches, and they don't come to clinical fields (p13)."

\subsubsection{No specific educational process}

This has caused some process steps to be eliminated from clinical training. Lack of education phases has made students' evaluation difficult. Most of the students believe that evaluations are unrealistic and superficial. Some process steps are not clear for the students such as clinical education aims and the type of skill that they should be learning specifically during that period. This leads to incorrect evaluation and also can result in uncertainty, wasted time, and frustration for students. "The previous term we went to field ever morning day from Saturday to Wednesday and we practice the same thing. We really spent time to clinical education but are not objective. Most of them are unclear ( $p 4)$." 


\subsubsection{Irresponsibility in the form of mentoring}

A mentorship program is a way to improve clinical competency and education skills. However, lack of instructor accountability and failure to create ongoing communication between instructors and mentors has caused mentorship program outcome to be less than satisfactory. "We couldn't handle the patients. And the head nurses entrusted repetitive tasks to us. It was the same as the BS level, and there is no difference. We even learned more in the BS. And they evaluated us and assign a score to us. But we didn't learn anything. At least the instructors did not see whether or not we learned anything from the mentors ( $p 7)$."

\section{Discussion}

The finding is pathology of MS critical care apprenticeships. One of the main categories was "ineffective management." Educational mangers have faced difficulties such as shortages of instructors and clinical fields when they want to plan. This problem leads to missing and reducing some outlines. In addition, managers have to assign students in general wards. However, they can prevent such problems in clinical education with proper planning. Reducing the period of apprenticeships will decrease the quality of education and opportunities for practicing skills. Some researchers also believe that the lack of knowledge and exposure to practical situations cause an inability to apply theory in practice (13). Planning of clinical education requires quality analysis and control such as in other areas of education (14). The results have shown that poor planning is an important factor in decreasing students' performance efficiency. Delaram (2006) found that most weaknesses in clinical education are lack of coordination between staff expectations and educational objectives, ignoring students' opinions in planning and their decisionmaking abilities, imbalance between the number of students and patients in a ward, inadequate resources, failure to use the educational instruments, and lack of students' evaluation (15). Nursing education curriculums should be designed to provide opportunity for mastering and acquisition clinical skills in addition to intellectual development of students (16). Improving the current status of clinical nursing education requires more attention to purposeful planning and developing appropriate process for evaluation of an educational curriculum. Strengthening the capacity of clinical instructors also can lead to the improvement of clinical education (17). The results showed that the recruitment of specialist in apprenticeships has caused providing nursing care based on nursing process to be missed. Another study showed that, traditionally, nursing education and a mechanical approach to human behavior can cause an inflexible approach to nurses' training. These behaviors have been criticized because of ignoring education of caring behaviors in teaching. While caring is the core of nursing. Traditionally nursing education cannot develop caring behavior of students (18). The second main category is an "unfavorable context for obtaining skills." Students encounter systemic barriers for obtaining skills, including lack of nurses' cooperation in providing patient care and using existing equipment, along with unpleasant organizational climates such as disrespect for the students' dignity. Therefore, poor communication and lack of nurses' cooperation reduce learning opportunities and create an unfavorable educational climate in practice. In other studies, the lack of coordination between staff and students is a significant problem in clinical education (15). Other studies found that conflict, tension, and lack of real experiences were obstacles in clinical education (19). Other research identified challenges such as stress, anxiety and confusion, fear of harm to patients, self-blame, low self-esteem, suffering from patients' pain, fear, and unpleasant feelings such as shame, incompetence, and hopelessness (20). However, effective education depends on different factors, including atmosphere of educational space. Educational environment with respect and mutual communication can reduce stress and promote students' confidence. This not only facilitates learning but also enhances interest in clinical settings and willingness to work with patients. This can lead to effective patients' care. Achieving satisfactory learning without an environment with healthy components is difficult (17). A remarkable point of the study results is lack of clinical setting fitness for obtaining experience and skills by critical care nursing students. Hence, they often cannot gain experience in specific procedures, although clinical education constitutes an important part of nursing education. Only in this way, learned theoretical knowledge transmits to practice and clinical settings, and student can meet with patients and their problems and play a real role as a nurse (21). Lack of opportunity to carry out standard procedures and unfavorable clinical situations are negative factors affecting apprenticeships. Nowadays, multidimensional and masterly nursing care in different wards is crucial. Thus, nursing students need to be prepared for their task as clinical care providers in environments where information and clinical situations are constantly changing (22). Lack of knowledge and professional skills is among the most important clinical education problems (23). Nursing students' experiences of the clinical education have been reported as anxiety, lack of motivation and the gap between theory and practice (24). The third category in this study is "lack of clinical instructors with sufficient competence." Thus, implementation of critical care nursing curriculum is difficult. In other studies, factors such as the absence of sufficient clinical instructors to meet educational needs and lack of incentives for students are the most important for clinical education from a students' point of view (25). 
In another study, most participants have pointed to the inadequate efforts of teachers to perform their duties well, due to their lack of proficiency in the education. In addition, all participants confirmed the necessity of instructors' evaluation according to the suitable indicators. They believe that, although recruitment of qualified instructors plays an important role in clinical education, the current method has drawbacks because of being strict and must provide attention to the degree and publications without any attention to their clinical skills (26). Peyman et al. (17) revealed that the most important factors from a students' perspective that affect clinical education were instructors, dealing with students, and evaluation, respectively. The authors also believed that student information of curriculum objectives, evaluation, coordination between objectives, students' expectations, duties and clinical facilities, and sufficient patients are important factors. However, only $50 \%$ of students stated that clinical instructors are experts in clinical issues (17). The results indicated that the absence of specific educational process is an important factor in reducing the effectiveness of clinical education. One of the main problems in the Peyman et al. study was that it offered no clear job description in clinical education (17). Other studies have mentioned barriers to achieving the goals of clinical education, including unclear clinical education objectives, stressful environment, low willingness of experienced instructors to participate in the clinical environment, lack of coordination between theory and clinical practice, and lack of educational and welfare facilities (23). However, the current status of clinical nursing education requires more attention to review of methods of clinical evaluation and the provision of facilities and equipment if faculties want to achieve continuous quality improvement. Purposeful planning and designing appropriate processes for evaluating educational programs, as well as strengthening the capacity of clinical instructors, can lead to clinical education improvement (17). The results indicate that allocating students to wards without coordination and unclear educational processes have caused students to feel exploited due to non-nursing activities. Wasting of time and loss of motivation and sense of neglect are major consequences. However, the recruitment of experienced mentors affects students' clinical learning outcomes (24).

\section{Conclusions}

The results indicate that ineffective management and lack of suitable contexts for learning and experience, lack of clinical instructors, and inadequate competency are important factors in the pathology of clinical education for critical care nursing. Preparing fields for entering critical care nursing students, especially provisions for an adequate clinical training field and faculty members, provision workshops for instructors, orientation before starting apprenticeships, and recruiting competent instructors can improve clinical education quality. Using clinical nurse managers as evaluators on apprenticeships and coordination between clinical fields and theoretical education are notable.

\section{Acknowledgments:}

The research study was supported by Tehran University of Medical Sciences, international campus (TUMS-IC).

\section{Conflict of Interest:}

There is no conflict of interest to be declared.

\section{Authors' contributions:}

All authors contributed to this project and article equally. All authors read and approved the final manuscript.

\section{References:}

1) Mondor, Eugene E. Knowledge acquisition, knowledge retention and job satisfaction among registered nurses following a critical care education program. (Master of Nursing), University of Alberta. Thesis/dissertation. 2004.

2) Aitken LM. Critical care nurses' use of decision - making strategies. J Clin Nurs. 2003; 12(4): 476-83. doi: 10.1046/j.1365-2702.2003.00763.x. PMID: 12790860.

3) Corcoran J, Nicholson C. Learning portfolios-evidence of learning: an examination of students' perspectives. Nurs Crit Care. 2004; 9(5): 230-7. doi: 10.1111/j.1362-1017.2004.00078.x. PMID: 15462121.

4) Menzel LK, Katz SM, Menting SA, Laack KD. Providing a critical care experience for undergraduate nursing students. Crit Care Nurse. 1998; 18(5): 47-53. PMID: 9934049.

5) Rattray JE, Paul F, Tully V. Partnership working between a Higher Education Institution and NHS TRUSTS: developing an acute and critical care module. Nursing in critical care. 2006; 11(3): 111-7. doi: 10.1111/j.1362-1017.2006.00166.x. PMID: 16719016.

6) Nibert AT. New graduates a precious critical care resource. Critical care nurse. 2003; 23(5): 47-50. PMID: 14606126. 
7) Riley-Giomariso O. Mirroring the human circumstance: An interpretive phenomenological study of student encounters in critical care. Theses and Dissertations School of Nursing. University of Maryland, Baltimore. 1998.

8) Sanatkhani M, Molla Z, Akbari M. Evaluation of the Students' Perception about Clinical Education and Examination in Mashhad School of Dentistry (Iran) in 2009. Journal of Mashhad Dental School. 2012; 36(3): 211-22.

9) Khademolhoseini SM, Alhani F, Anooshe M. Pathology of clinical training in nursing students of intensive care unit: A qualitative study. IJCCN. 2009; 2(2): 81-6.

10) Kerfoot K, Wantz SL. Compliance leadership: The 17th century model that doesn't work. Nursing Economics. 2003; 21(1): 42. PMID: 12632720.

11) Graneheim UH, Lundman B. Qualitative content analysis in nursing research: concepts, procedures and measures to achieve trustworthiness. Nurse Educ Today. 2004; 24(2): 105-12. doi: 10.1016/j.nedt.2003.10.001. PMID: 14769454.

12) Guba EG, Lincoln YS. Competing paradigms in qualitative research. Handbook of qualitative research. 1994; 2: 105-17.

13) De Swardt HC. A description of the theoretical and practical experiences of critical care nursing students. 2009. Available from: http://uir.unisa.ac.za/handle/10500/1781.

14) Heidari F, Ahmadi GA. identifying problems and offering solutions a curriculum to meet the curriculum evaluation process. Curriculum planning knowledge \& research in educational sciences. 2013; 2(9): 12636.

15) Delaram M. Clinical education from the viewpoints of nursing and midwifery students in Shahrekord University of Medical Sciences. Iranian journal of medical education. 2006; 6(2): 129-35.

16) Zhang Lf. From conceptions of effective teachers to styles of teaching: Implications for higher education. Learning and individual differences. 2009; 19(1): 113-8. doi: 10.1016/j.lindif.2008.01.004.

17) Peyman H, Darash M, Sadeghifar J, Yaghoubi M, Yamani N, Alizadeh M. Evaluating the viewpoints of nursing and midwifery students about their clinical educational status. Iranian Journal of Medical Education. 2011; 10(5): 1121-30.

18) Nikfarid L, Rasouli M. Caring curriculum: a new paradigm in nursing education. 2011; 24(70): 61-71.

19) Alavi M, Irajpour A, Nasiri A, Abedi H. Barriers to clinical education: Student nurses' Experiences. Modern Care Journal. 2009; 6(1): 5-11.

20) Khademian Z, Sharif F. nursing students' initial clinical experiences. IJNR. 2012; 7(26): 23-33.

21) Moon MS. Nursing students' initial clinical experience. The Journal of Korean Academic Society of Nursing Education. 1998; 4(1): 15-27.

22) Serena P, Anna B. Italian nursing students' perception of their clinical learning environment as measured with the CLEI tool. Nurse Education Today. 2009; 29(8): 886-90. doi: 10.1016/j.nedt.2009.05.016. PMID: 19576663.

23) Abedini S, Takhti HK, Abedini S. Assessing nursing curriculum: Graduate nurse viewpoints. Canadian Journal of Nursing Informatics. 2011; 6(3): 20-6.

24) Kristofferzon ML, Mårtensson G, Mamhidir AG, Löfmark A. Nursing students' perceptions of clinical supervision: The contributions of preceptors, head preceptors and clinical lecturers. Nurse education today. 2013; 33(10): 1252-7. doi: 10.1016/j.nedt.2012.08.017. PMID: 22995594.

25) Williams AF. An antipodean evaluation of problem-based learning by clinical educators. Nurse Education Today. 1999; 19(8): 659-67. doi: 10.1054/nedt.1999.0369. PMID: 10855145.

26) Pourghane P. Nursing students' experiences of clinical teaching: a qualitative study. Holistic Nursing And Midwifery Journal. 2013; 23(2): 16-26. 